\title{
Vitamin K supplementation increases vitamin $K$ tissue levels but fails to counteract ectopic calcification in a mouse model for pseudoxanthoma elasticum
}

\author{
Theo G. M. F. Gorgels • Jan H. Waarsing • Marjolein Herfs • Daniëlle Versteeg • \\ Frank Schoensiegel • Toshiro Sato • Reinier O. Schlingemann • Boris Ivandic • \\ Cees Vermeer • Leon J. Schurgers • Arthur A. B. Bergen
}

Received: 26 November 2010 /Revised: 14 June 2011 / Accepted: 16 June 2011 /Published online: 2 July 2011

(C) The Author(s) 2011. This article is published with open access at Springerlink.com

\begin{abstract}
Pseudoxanthoma elasticum (PXE) is an autosomal recessive disorder in which calcification of connective tissue leads to pathology in skin, eye and blood vessels. PXE is caused by mutations in ABCC6. High expression of this transporter in the basolateral hepatocyte membrane suggests that it secretes an as-yet elusive factor into the circulation which prevents ectopic calcification. Utilizing our $A b c c \sigma^{--}$mouse model for PXE, we tested the hypothesis that this factor is vitamin $\mathrm{K}$ (precursor) (Borst et al. 2008, Cell Cycle). For 3 months, $A b c c \sigma^{-1}$ and wildtype mice were put on diets containing either the minimum dose of vitamin $\mathrm{K}$ required for normal blood coagulation or a dose that was 100 times higher. Vitamin $\mathrm{K}$ was supplied as menaquinone-7 (MK-7). Ectopic calcification was monitored in vivo by monthly micro-CT scans of the snout, as the PXE mouse model develops a characteristic connective tissue mineralization at the base of the whiskers.
\end{abstract}

T. G. M. F. Gorgels $(\bowtie) \cdot$ D. Versteeg • A. A. B. Bergen

Department of Clinical and Molecular Ophthalmogenetics,

The Netherlands Institute for Neuroscience (NIN),

an Institute of the Royal Netherlands Academy of Arts and

Sciences (KNAW),

Meibergdreef 47,

1105 BA Amsterdam, The Netherlands

e-mail: t.gorgels@nin.knaw.nl

J. H. Waarsing

Department of Orthopaedics, Erasmus Medical Center,

Dr. Molewaterplein 50-60,

Rotterdam, The Netherlands

M. Herfs $\cdot$ C. Vermeer $\cdot$ L. J. Schurgers

VitaK and Cardiovascular Research Institute CARIM,

Maastricht University,

Maastricht, NL, The Netherlands
In addition, calcification of kidney arteries was measured by histology. Results show that supplemental MK-7 had no effect on ectopic calcification in $\mathrm{Abcc}^{-/}$mice. MK-7 supplementation increased vitamin $\mathrm{K}$ levels (in skin, heart and brain) in wild-type and in $A b c c \sigma^{/-}$mice. Vitamin $\mathrm{K}$ tissue levels did not depend on Abcc6 genotype. In conclusion, dietary MK-7 supplementation increased vitamin $\mathrm{K}$ tissue levels in the PXE mouse model but failed to counteract ectopic calcification. Hence, we obtained no support for the hypothesis that Abcc6 transports vitamin K and that PXE can be cured by increasing tissue levels of vitamin $\mathrm{K}$.

Keywords Pseudoxanthoma elasticum - ABC transporter . Vitamin K · Ectopic calcification · Vascular calcification . Connective tissue $\cdot$ Cardiovascular $\cdot$ Vitamins $\cdot$ Calcium metabolism $\cdot$ Mouse models

F. Schoensiegel $\cdot$ B. Ivandic

Department of Medicine III, Cardiology, University of Heidelberg, Im Neuenheimer Feld 410,

69120 Heidelberg, Germany

T. Sato

J-Oil Mills,

Fukuroi City, Japan

A. A. B. Bergen

Department of Clinical Genetics, Academic Medical Center,

Meibergdreef 9,

Amsterdam, The Netherlands

R. O. Schlingemann • A. A. B. Bergen

Department of Ophthalmology, Academic Medical Center,

Meibergdreef 9,

Amsterdam, The Netherlands 


\section{Introduction}

PXE is an autosomal recessive disease characterized by progressive mineralization of connective tissue [1-4]. Clinically important sites of calcification are elastic layers in skin, Bruch's membrane of the eye and vascular arteries. The calcification leads to skin lesions, vision loss and various cardiovascular complications.

Positional cloning indicated that PXE is caused by mutations in $A B C C 6[5,6]$. Inactivation of $A b c c 6$ in the mouse resulted in the development of a PXE-like phenotype with calcification in eye, skin and blood vessels [7, 8]. This confirmed the role of ABCC6 in PXE and provided us with an animal model for PXE.

$A B C C 6$ encodes a member of the ABCC family of organic anion transporters [9]. The protein is prominently expressed in liver and kidney but virtually absent from the affected sites [10-12]. In the liver, ABCC6 localizes to the basolateral membrane of the hepatocyte $[7,13]$, where it is supposed to transport its substrate from the cytoplasm into the circulation. Mutations that impair this transport function cause PXE [14]. These findings suggested that PXE is a metabolic disease brought about by changes in circulating factors that occur when the ABCC6 pump is not functioning properly [15]. Recent studies provide strong experimental evidence for this hypothesis. Serum from PXE patients caused abnormal elastic fibre formation in cultures of fibroblasts, irrespective of whether fibroblasts were derived from PXE patients or from unaffected individuals [16]. Jiang et al. [17] demonstrated that muzzle skin transplants of $A b c c \sigma^{-1-}$ mice grafted onto wild-type (wt) mice remained normal, whereas wt transplants grafted onto $A b c c \sigma^{-1}$ mice developed ectopic calcification.

Several studies implicate vitamin K in the pathophysiology of PXE. An intriguing finding was that patients with a mutation in the gamma-glutamyl carboxylase $(G G C X)$ gene develop PXE-like symptoms [18]. GGCX catalyzes the vitamin K-dependent carboxylation of glutamate residues to calcium-binding gamma-glutamate (Gla) residues. During this reaction, the hydroquinone form of vitamin $\mathrm{K}$ is oxidized to its epoxide form. A small number of proteins require $\gamma$-carboxylation for their activity. This group includes several clotting factors as well as proteins involved in calcification, such as matrix Gla-protein (MGP). MGP is an inhibitor of tissue calcification [19]. Interestingly, carboxylation of MGP was found to be reduced in PXE patients [20, 21] and in the $A b c c \sigma^{/-}$mouse [22]. Recently, Vanakker et al. [21] reported that PXE patients have reduced vitamin $\mathrm{K}$ serum levels.

These data suggest that PXE symptoms are caused by a local deficiency in vitamin K-dependent protein carboxylation. They support the "PXE-K hypothesis" [23], which postulates that vitamin $\mathrm{K}$ (or a precursor of vitamin $\mathrm{K}$ ) is the substrate of the ABCC6 pump. It is known that vitamin $\mathrm{K}$, once it is taken up by the digestive system and brought into the blood, is avidly taken up by the liver [24]. Here, it can be used in the production of clotting factors. According to the PXE-K hypothesis, ABCC6 protein exports vitamin $\mathrm{K}$ (precursor) from the hepatocyte back into the bloodstream. This will carry it to the periphery, where vitamin K dependent $\gamma$-carboxylation of MGP prevents calcification. Inactivation of $A B C C 6$ would thus lead to shortage of vitamin $\mathrm{K}$ in extra-hepatic tissues and failure to prevent spontaneous calcification in these tissues.

The PXE-K hypothesis implies that providing the periphery with functional vitamin $\mathrm{K}$ will prevent PXE. In the present study, we tested this hypothesis by supplementing vitamin $\mathrm{K}$ to the animal model for PXE, the $A b c c 6^{-1}$ mouse [7]. A high dose of vitamin $\mathrm{K}$ was added to the food, aiming to achieve high blood levels, which would allow for a sufficient amount of vitamin $\mathrm{K}$ to bypass the liver and reach the periphery. Vitamin $\mathrm{K}$ is a group name for several structurally related molecules, including phylloquinone (vitamin $\mathrm{K}_{1}$ ) and menaquinones ( $\mathrm{K}_{2}$ vitamins) [24]. Menaquinones (MK) are classified by the length of their aliphatic side chain (MK-n). We chose MK-7 for the dietary supplementation. While all forms of vitamin $\mathrm{K}$ serve as a co-factor in the $\gamma$-carboxylation of glutamate, MK-7 has a relatively long half-life (3 days) in the blood $[25,26]$ suggesting that this form of $\mathrm{K}$ is apt to escape rapid sequestration by the liver and reach extrahepatic, peripheral tissues. As biomarker for PXE symptoms in the mouse, we chose the mineralization of the connective tissue capsule surrounding the blood sinus at the base of the whiskers [27]. Mineralization was monitored in vivo by X-ray micro-computed tomography (micro-CT). After a 3-month diet, mice were sacrificed, and vitamin $\mathrm{K}$ content and tissue distribution were determined.

\section{Materials and methods}

Mice

$A b c c \sigma^{/-}$mice were generated in a hybrid background of C57BL/6 and 129/Ola and then backcrossed to C57BL/6 [7]. In the present study, we used mice that had been backcrossed to $\mathrm{C} 57 \mathrm{BL} / 6$ for ten generations. Abcc6 proficient $\left({ }^{+/+}\right)$littermates and pure C57BL/6 mice were used as wt control mice. Mice were bred in our animal facilities and kept in 12-h light-dark cycle of 50-80 lx with water and food (Teklad 2918, Harlan Teklad, Madison, WI) ad libitum. All animal studies were approved by an independent animal ethical committee under Dutch law. 
Vitamin K supplementation

We designed two diets. One diet contained vitamin $\mathrm{K}$ in the minimum dose required (MDR) $(1 \times \mathrm{MK}-7$ diet), the other 100 times as much $(100 \times$ MK-7 diet $)$. The diets were made by mixing MK-7 (Kind gift of J-Oil Mills, Nakashinden, Fukuroi City, Japan; dissolved in sunflower oil) with a mouse food lacking vitamin K (diet \#4165.00, in powder form, Arie Blok Diervoeding, Woerden, NL). The MDR for rodents is about $0.25-0.5 \mu \mathrm{g} / \mathrm{g}$ food [28], based on blood coagulation. Our diets contained $0.25 \mu \mathrm{g}$ MK-7 (1×MDR) or $25 \mu \mathrm{g} \mathrm{MK}-7(100 \times \mathrm{MDR})$ per gram food.

Mice were divided into two equal groups of five $A b c c \sigma^{-1}$ and six wt mice (four $A b c c \sigma^{+/+}$and two C57BL/ 6). One group received the $1 \times \mathrm{MK}-7$ food, the other the $100 \times$ MK-7 food. The food was provided ad libitum. The diet started at 1 year of age and lasted for 3 months.

In vivo measurement of calcification in the muzzle

$A b c c \sigma^{/-}$mice develop calcification in the capsule surrounding the blood sinus at the base of the whiskers [8]. We in vivo monitored development and progression of this calcification by micro-CT scans of the snout using a Skyscan 1076 (SkyScan, Kontich, Belgium). Scans were made using a 1-mm Al filter, the source set at $40 \mathrm{kV}$ with a current of $250 \mu \mathrm{A}$ and a rotation step of $1.5^{\circ}$. During the scan, mice were anaesthetized by isoflurane inhalation, and the condition was monitored visually using a camera and by measuring the rhythm of breathing. A scan of the muzzle area took about $10 \mathrm{~min}$. Scans were done once a month. The first one was done at the start of the diet. After 3 months, the experiment was stopped.

From the scans, a 3D reconstruction of the snout was made resulting in datasets with an isotropic voxel size of $35 \mu \mathrm{m}$ using software supplied with the scanner. In these reconstructions, both normal calcifications of skull and teeth and ectopic calcification of blood sinuses were clearly visible. Using an in-house-made Matlab software tool (Matlab r2007b, The Mathworks, Natick, MA, USA), calcification of skull and teeth was removed automatically from the datasets. The remaining pathological calcification in sinus capsules was quantified by assessing total mineralized volume after applying a density threshold. The fixed threshold was chosen such that the dynamics in sinus calcification were optimally represented.

Ex vivo measurement of calcification in the kidney

$A b c c \sigma^{/-}$mice spontaneously develop calcification in the walls of arteries in the kidney cortex [7, 29]. This vascular calcification phenotype was quantified ex vivo, in paraformaldehyde-fixed and paraffin-embedded kidneys by two methods: micro-CT and histology.

Kidneys were scanned in a Skyscan 1076 micro-CT scanner (Skyscan, Kontich, Belgium) using a $0.5-\mathrm{mm} \mathrm{Al}$ filter, the source set at $55 \mathrm{kV}$ and $181 \mu \mathrm{A}$ and a rotation step of $0.5^{\circ}$, resulting in datasets with a $9-\mu \mathrm{m}$ isotropic voxel size. After manually removing calcification in pelvis and tubules from the images, the total volume of the calcifications in the renal cortex was automatically determined using Matlab.

Next, sagittal sections of $6 \mu \mathrm{m}$ were cut of the kidney, and five sections per mouse, each separated by $180 \mu \mathrm{m}$, were stained for calcification according to von Kossa. In these sections, we counted the number of von Kossa positive blood vessel profiles in the kidney cortex and calculated the average number per section [29]. Micrographs were taken with a Zeiss Axioplan 2 (Carl Zeiss AG, Germany) equipped with an Evolution MP camera (MediaCybernetics, Bethesda, USA) and Image-Pro Plus acquisition software (version 6, MediaCybernetics, Bethesda, MD, USA).

\section{Tissue collection}

Mice were anaesthetized and sacrificed by cervical dislocation. Several organs were collected and either fixed in 2\% paraformaldehyde in $0.1 \mathrm{M}$ phosphate buffer, $\mathrm{pH} 7.4$, or frozen in liquid $\mathrm{N}_{2}$ and stored at $-20^{\circ} \mathrm{C}$. For histopathology, paraformaldehyde-fixed tissue was embedded in paraffin. Sections were stained with haematoxylin-eosin and von Kossa using standard procedures.

\section{Vitamin K measurement}

Concentrations of vitamin $\mathrm{K}\left(\mathrm{K}_{1}\right.$ and $\left.\mathrm{K}_{2}\right)$ were analyzed by HPLC as described previously [30]. Briefly, part of the tissue was weighed and homogenized in ethanol/water $(v / v)$ at a ratio 1:2 using a blender (Ultra Turrax, Janke and Kunkel, Staufen, Germany). Homogenized samples were supplemented with vitamin $K_{1}$ (25) (GLSynthesis, Worcester, USA) as an internal standard, extracted with four volumes of n-hexane and pre-purified on silica columns. Quantification of vitamin $\mathrm{K}$ was performed by RP-HPLC using fluorescence detection after post-column reduction on a zinc column (Riedel-DeHaën, Seelze, Germany) at $40^{\circ} \mathrm{C}$. The mobile phase consisted of ethanol/acetonitrile/reduction buffer/water at a ratio $(v / v)$ of 360:90:4:3 and was degassed continuously with helium. Reduction buffer contained: $1 \mathrm{M}$ $\mathrm{ZnCl}_{2}, 1 \mathrm{M} \mathrm{NaOAc}$ and $1 \mathrm{M} \mathrm{AcOH}$ in $\mathrm{MeOH}$.

\section{Statistics}

In order to analyze dynamics of muzzle calcification during the diet period we performed regression analysis for each 
mouse with either the actual calcification value or the logtransformed calcification as dependent variable and diet duration as independent variable in SPSS (version 16). The $R^{2}$ adjusted of the linear and logarithmic regression was calculated to assess the quality of the fit. To formally describe the relation between calcification, diet and time (diet duration), we performed a linear mixed model analysis (in SPSS, version 16). The following parameters were included in the model: the $\log$ of the volume of ectopic calcification, measured by micro-CT, as dependent variable, diet as factor and time (diet duration) as covariate. Fixed effects in the analysis were diet, time and their interaction. The analysis was performed with a random intercept (to account for difference in start position) and random slope (to account for difference in slope) per mouse. Statistical analysis of the effect of MK-7 supplementation on kidney cortex calcification was done with Student's $t$ test.

The effect of diet and genotype on tissue levels of various vitamin $\mathrm{K}$ forms was analyzed by ANOVA in SPSS (version 18) with vitamin $\mathrm{K}$ level as dependent variable and diet and genotype as fixed factors. Since Levene's homogeneity test for equality of variances indicated that variances were often unequal between the groups, this ANOVA was performed on rank-transformed data. Missing measurement values (presumably below detection limit) were not included in the ranking. The variance in the rank-transformed data was homogeneous (Levene's test).

\section{Results}

Dietary vitamin K supplementation

To examine the effect of supplemental vitamin $\mathrm{K}$ on the PXE phenotype, we prepared two diets differing in vitamin $\mathrm{K}$ content $(1 \times \mathrm{MK}-7,100 \times \mathrm{MK}-7)$, fed these for 3 months to $A b c c \sigma^{-1}$ and wt mice and monitored calcification in the animals. Vitamin K was supplied as MK-7. The diets did not cause overt discomfort to the mice. One mouse died during the experiment, 1 month before the end of the diet period. This was an $A b c c \sigma^{--}$mouse on the $100 \times$ MK-7 diet. The cause of death was not determined.

Effect of dietary vitamin K supplementation on calcification in the muzzle

A prominent feature of the pathology of $A b c c \sigma^{--}$mice is spontaneous calcification of the capsule surrounding the blood sinus at base of the whiskers [8]. Mice have 25-27 large whiskers on each muzzle, arranged in five rows of 57 whiskers each [31]. We monitored the ectopic mineralization in this tissue in vivo by micro-CT of the snout.
Micro-CT scans of wt mice did not show any calcification of whisker sinus capsules at any time and dietary regime. In contrast, all $A b c c \sigma^{-1}$ mice had calcifications already at the start of the diet (Fig. 1). These consisted of shell-shaped calcifications of the whisker sinus capsule (Fig. 2). Not all whisker sinus capsules were mineralized at this stage. Follow-up scans showed a clear progression of the calcification (Fig. 3). Both number of capsules affected and extent of calcification in each capsule increased during the diet period.

To quantify the ectopic calcification, we used the 3D reconstructed micro-CT image of the snout, applied a density threshold for calcification, removed the dense signal of skull and teeth and calculated the volume of the remaining density as representing the ectopic calcification of the whisker capsule. Graphs of changes in calcification volume over time are shown in Fig. 4. The graphs for the individual mice illustrate the large individual differences. The mice which we had assigned to the $1 \times \mathrm{MK}-7$ diet group happened to have slightly more calcification at the start of the diet than the mice on the $100 \times \mathrm{MK}-7$ diet. Please note that calcification increased during the diet period in all mice, in both diet groups. Regression analysis indicated that progression of calcification during the diet period is well described by an exponential model (log calcification volume vs. time, average $R^{2}$ adjusted=0.94) or a linear model (calcification volume vs. time, average $R^{2}$ adjusted= 0.93). Calcification volume increased considerably (3-4fold) in both diet groups over the 3-month diet period.

To formally describe the relation between volume of ectopic calcification, diet and time (diet duration), we performed a linear mixed model analysis with the log of the calcification as dependent variable. The analysis showed that calcification increased with time $(P=0.001)$, but this progression was not dependent on diet $(P$ interaction $=0.976)$.

In summary, our in vivo measurements showed that the 100-fold increase in dietary MK-7 had no significant effect on the pace of mineralization in whisker sinus capsules of $\mathrm{AbccF}^{-/}$mice.

Effect of dietary vitamin K supplementation on calcification in the kidney

Calcification of walls of arteries is an important clinical feature of PXE. In the $A b c c \sigma^{1-}$ mouse, this phenotype is particularly prominent in the kidney cortex. We visualized this calcification ex vivo by two methods: First, micro-CT scans were made of the isolated kidney. Next, the kidney was sectioned, and a sample of sections was stained for calcification by von Kossa.

While wt mice had no distinct renal cortex calcifications, all $A b c c \sigma^{1-}$ mice showed mineralization of arteries in the cortex (Fig. 5). Calcification was quantified by measuring 
Fig. 1 In vivo micro-CT imaging of calcification in the muzzle. X-ray image and cross sections of the $3 \mathrm{D}$ reconstructed micro-CT image of the rostral part of the head of a wt (left) and $\mathrm{AbcC}^{-1}$ (right) mouse. Skull and teeth are clearly visible, both in wt and $\mathrm{AbccF}^{/-}$mouse. In addition, the $A b c c \sigma^{-1}$ mouse has shell-shaped calcified profiles (arrows) in the muzzles as illustrated by the cross-sections. Coloured lines indicate positions of the cross-sectional planes
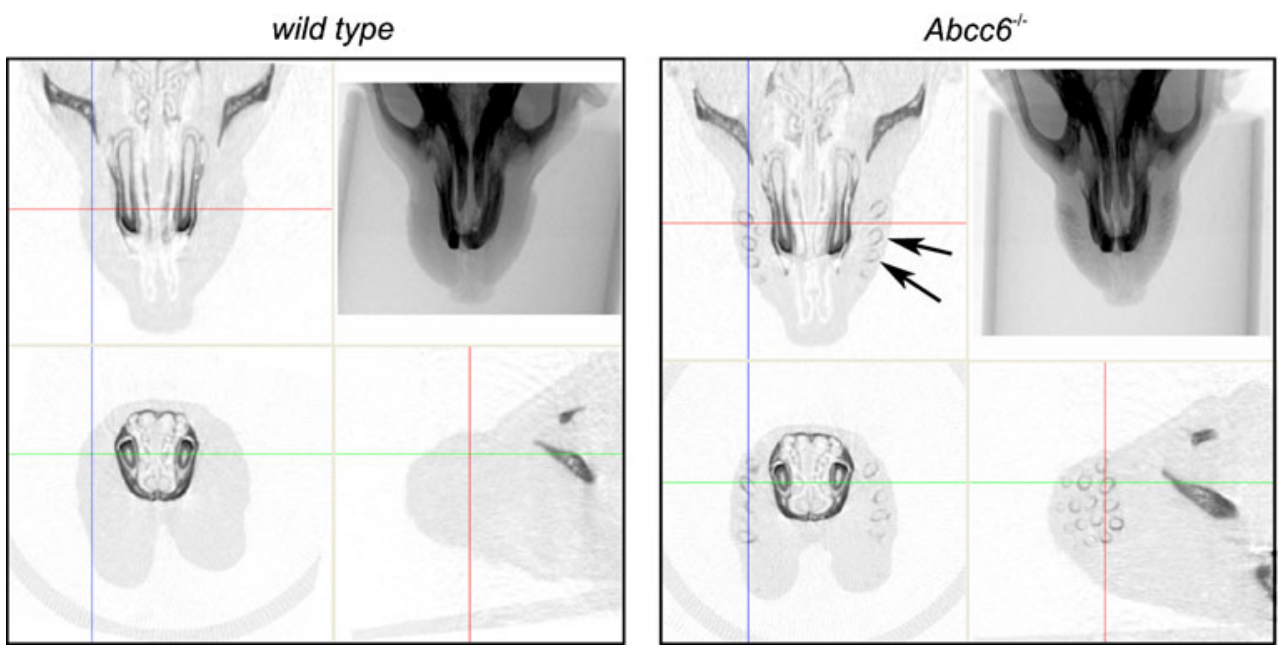

the total volume of calcified objects in the kidney cortex by micro-CT, and secondly, by counting the number of calcified profiles in the histological sections. The correlation between the outcomes of both methods was high: a correlation coefficient of 0.98 was found for calcification in the $A b c c \sigma^{-1}$ mice. To determine the effect of diet on calcification in $A b c c \sigma^{--}$mice, we applied Student's $t$ test: no significant difference was found ( $P$ values 0.47 and 0.31 for histology and micro-CT, respectively; Fig. 5).

\section{Hepatic vitamin K levels}

To determine whether $A b c c 6$ genotype and dietary MK-7 concentration influence uptake and tissue distribution of vitamin $\mathrm{K}$, we sacrificed the mice at the end of the 3-month diet period and measured vitamin $\mathrm{K}$ levels in liver and several extra-hepatic tissues. Please note that the mice had received standard rodent chow until the start of experimental diets. During the experiment, they received vitamin K only in the form of MK-7.

Liver tissue samples were measured for vitamin $K_{1}$ and for MK-4, MK-6 and MK-7. Measurable levels of K- vitamers were found in liver samples of most wt and $\mathrm{Abcc}^{-/}$mice on $100 \times \mathrm{MK}-7$ diet. However, analysis of liver samples of mice on the $1 \times \mathrm{MK}-7$ diet often gave no measurable outcome, possibly because vitamin $\mathrm{K}$ levels in these samples were below detection threshold. For example, in the $1 \times$ MK-7 diet group, we obtained measurable MK-7 levels in only one out of six wt mice and in one out of five $A b c c \sigma^{-1}$ mice.

Figure 6 shows the measured vitamin $\mathrm{K}$ levels in the liver as function of diet and $A b c c 6$ genotype. In view of missing (presumably below detection limit) data points of the $1 \times \mathrm{MK}-7$ group, this plot underestimates the effect of supplementation. Nonetheless, it suggests that dietary MK-7 supplementation increased both MK-4 and MK-7 levels in liver. ANOVA indicated that MK-7 and MK-4 levels depended on supplementation $(P=$ 0.028 and 0.025 , respectively) but not on genotype (Table 1). Analysis of the effect of supplementation in $A b c c \sigma^{-1}$ mice separately did not yield significance, possibly because of the missing data points in the $1 \times$ MK-7 diet group. For MK- 6 and $\mathrm{K}_{1}$, no effect of supplementation was apparent.
Fig. 2 a Micro-CT scan of an $A b c c \sigma^{1-}$ mouse muzzle showing shell-shaped calcifications. b Paraffin section of the muzzle of an $A b c c \sigma^{--}$mouse (aged 9 months; $1 \times$ MK-7diet) stained with von Kossa localizes these calcifications (black) to the connective tissue capsule of the blood sinus of the whisker hair follicle. c Whisker follicle of a wt mouse (aged 8 months; $1 \times$ MK-7 diet) without calcification. Scale bar is $200 \mu \mathrm{m}$
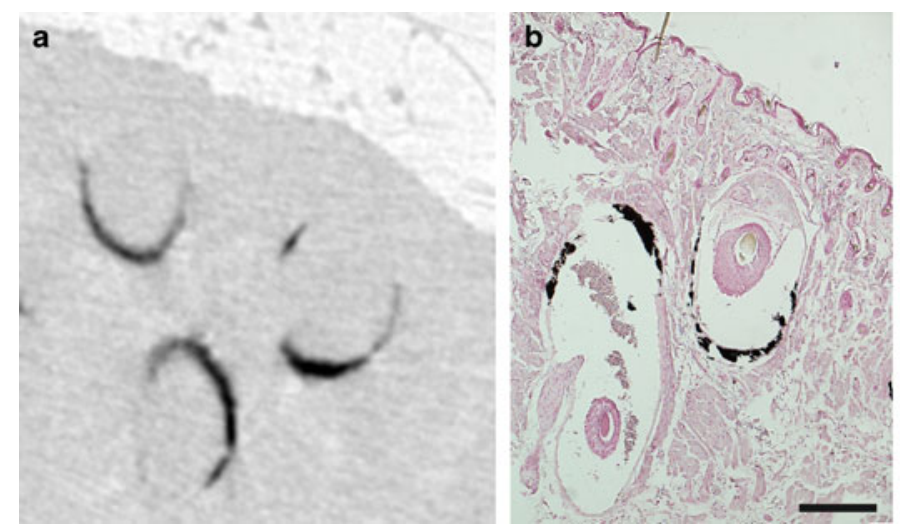

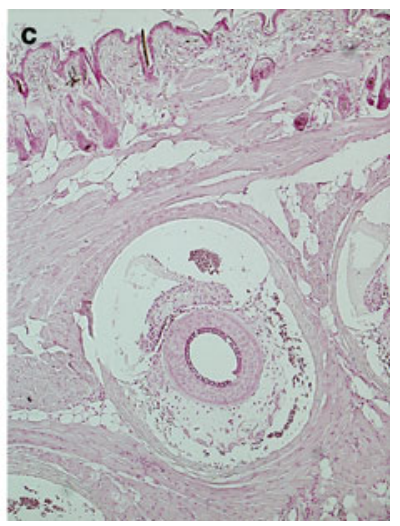



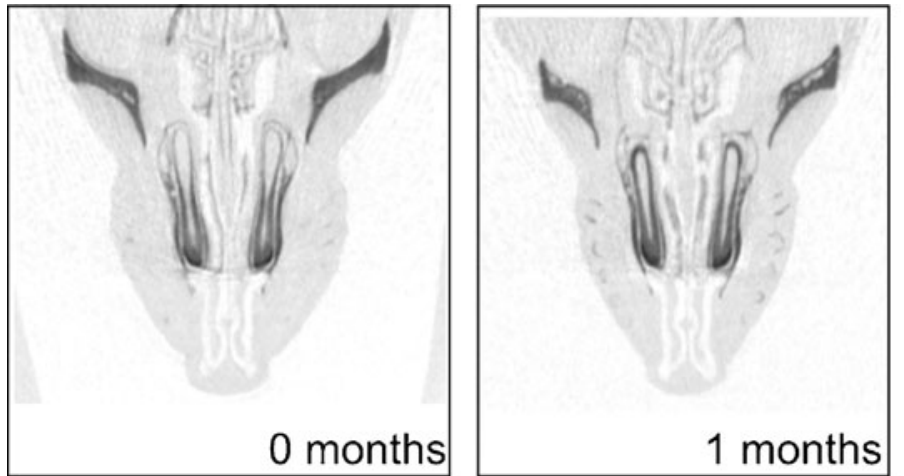

Fig. 3 Cross sections from micro-CT scans of an $A b c c \sigma^{1-}$ mouse (on $1 \times$ MK-7 diet) showing the in vivo progression in calcification of whisker sinuses, from the start of the diet $(0$ months $)$ until the end
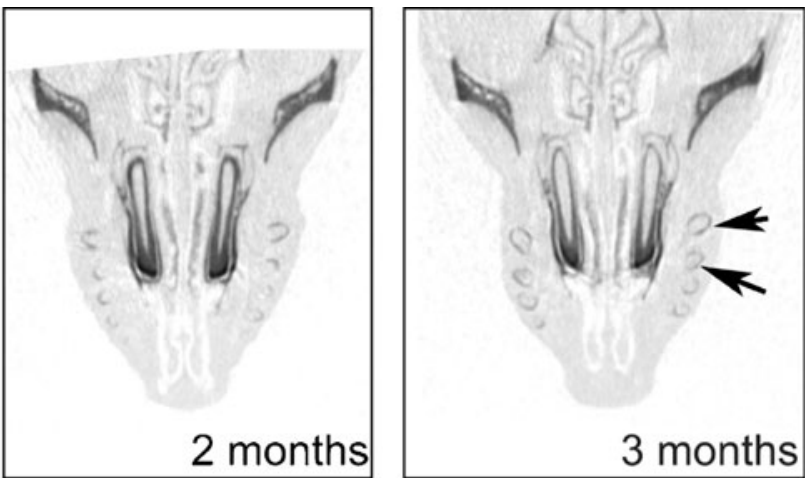

(3 months). Arrows point at whisker sinuses that are calcified after 3 months, whereas they were not calcified at the start of the diet

provide a rationale for an easily applicable therapy, i.e. vitamin $\mathrm{K}$ supplementation. We performed a dietary supplementation experiment using the PXE mouse model to test hypothesis as well as potential therapy. Our results do not lend support to the
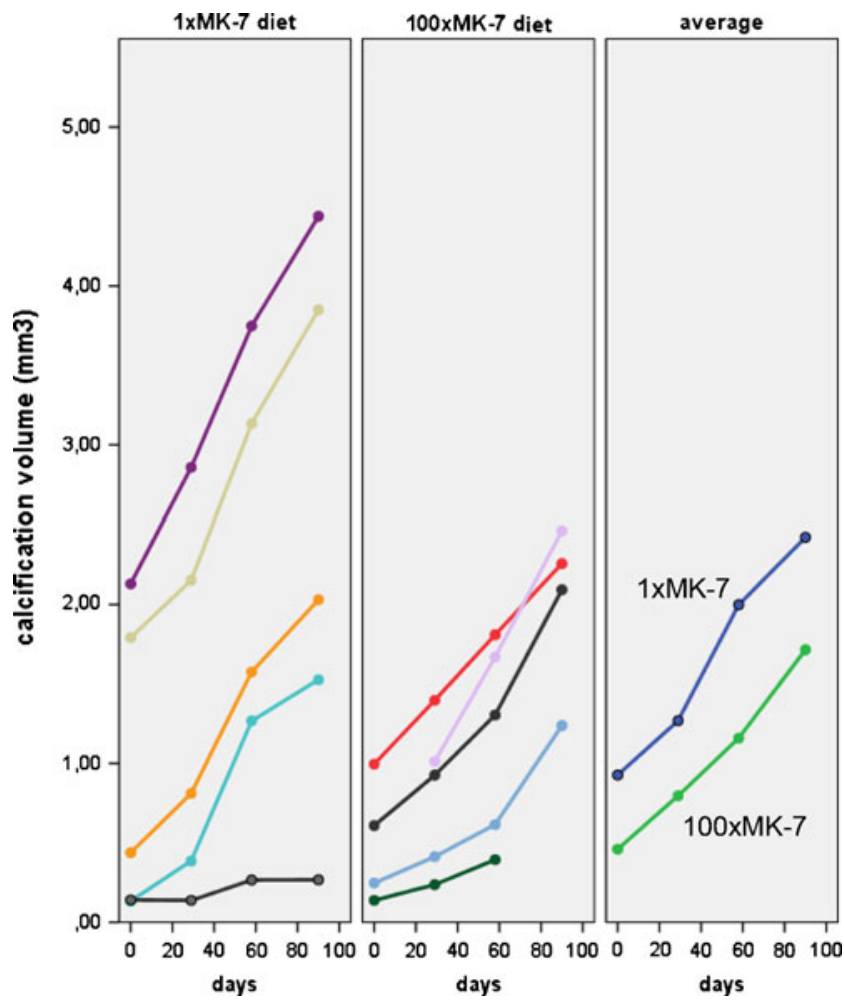

Fig. 4 Progression of calcification in the muzzles of $A b c c \sigma^{--}$mice from the start of the diet (time $=0)$ to the end, after 90 days. Coloured lines in the two graphs on the left depict the mineralization process in the individual mice. The graph on the right shows the averages per diet group (with missing values imputed). The $1 \times \mathrm{MK}-7$ diet group had, by chance, a slightly higher calcification at the start of the diet. Importantly, calcification progressed in all mice and no difference in the pace of calcification was noticed between the diets (for statistics, see Results) 

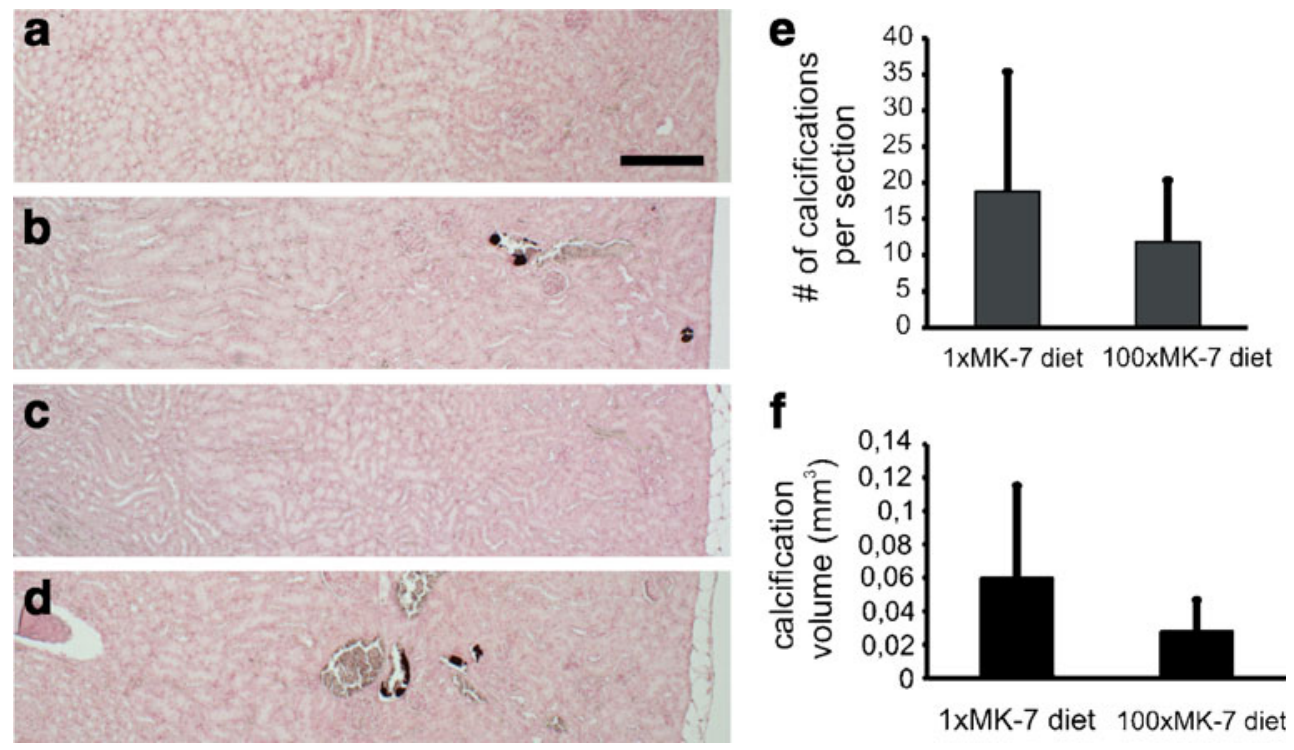

Fig. 5 Effect of vitamin K supplementation on calcification in arteries in the kidney cortex. a-d Kidney sections of wt (a, c) and $A b c c \sigma^{\prime-}$ mice $(\mathbf{b}, \mathbf{d})$ on $1 \times \mathrm{MK}-7(\mathbf{a}, \mathbf{b})$ or $100 \times \mathrm{MK}-7$ diet $(\mathbf{c}, \mathbf{d})$. Von Kossa staining shows calcification (black deposits) in walls of arteries in the cortex of $A b c c \sigma^{-1}$ mice on either diet. No calcifications were observed in wt mice. Cortex is on the right, medulla on the left. Bar is $200 \mu \mathrm{m}$. e Effect of diet on calcifications in arteries in the kidney cortex in $A b c c \sigma^{--}$mice, assessed by histology. Histograms represent

PXE-K hypothesis: first, we did not see a reduction of pathology (calcification) by feeding $A b c c \sigma^{-1}$ mice extra vitamin K. Secondly, vitamin K tissue levels did not depend on Abcc6 genotype. Thirdly, no correlation was found between ectopic calcification and vitamin $\mathrm{K}$ tissue levels.

Dietary MK-7 supplementation did not reduce ectopic calcification

To test the PXE-K hypothesis, we employed the $A b c c \sigma^{1-}$ mouse model for PXE [7, 8]. As measure of PXE mean number \pm standard deviation (s.d.) of calcified profiles per sagittal kidney section. Diet did not cause a significant difference in calcification ( $p=0.47$, Student's $t$ test). $\mathbf{f}$ Effect of diet on calcifications in arteries in the kidney cortex in $A b c c \sigma^{-1}$ mice, assessed by microCT. Histograms represent average volume $( \pm$ s.d.) of calcifications per kidney. Diet did not cause a significant difference in calcification $(p=$ 0.31 , Student's $t$ test)

pathology, we analyzed calcification in the connective tissue capsule that surrounds the blood sinus at the base of the whiskers [8]. This feature of $A b c c \sigma^{-1}$ mice has been used as a biomarker for ectopic mineralization in a number of studies [27]. An important advantage of this parameter is that it can be visualized and measured in vivo by micro-CT, as demonstrated in this study. This enabled us to monitor the mineralization process in individual mice during the diet period. This is particularly relevant, since inter-animal variation in the extent of calcification can be large, which can hamper statistical analysis when only endpoints are
Fig. 6 Vitamin K levels ( \pm s.d.) in the liver as function of diet and $A b c c 6$ genotype. Please note that some data points (mainly in the $1 \times \mathrm{Mk}-7$ diet group) were missing (as indicated by an absence of an error bar) presumably because the levels were below detection threshold

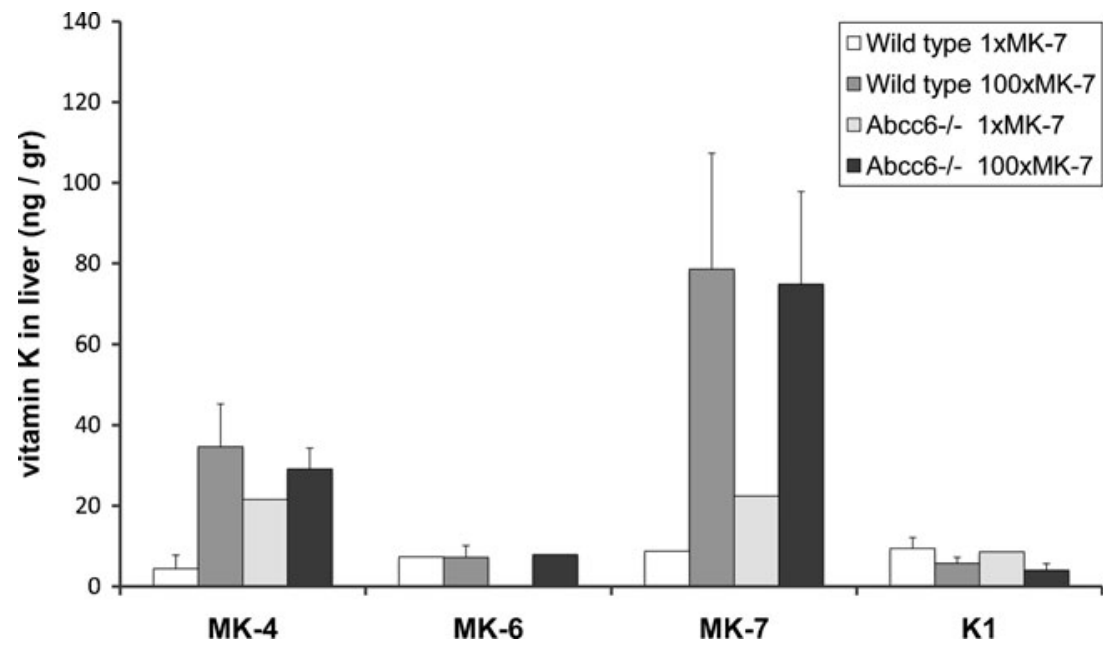


Table 1 ANOVA of the effect of diet and $A b c c 6$ genotype on vitamin $\mathrm{K}$ tissue levels
The analysis compared two diets with 100-fold difference in MK-7 content $(P$ values of ANOVA on rank-transformed data, see M\&M. $P$ values $<$ 0.05 are italicized)

${ }^{\mathrm{a}}$ Not enough data points

\begin{tabular}{|c|c|c|c|c|c|c|}
\hline & & \multicolumn{3}{|c|}{ All mice } & \multirow{2}{*}{$\begin{array}{l}\text { Wild type } \\
\text { Diet }\end{array}$} & \multirow{2}{*}{$\begin{array}{l}\text { Abcc6 } \\
\text { Diet }\end{array}$} \\
\hline & & Diet & Genotype & Interaction $\operatorname{diet} \times$ genotype & & \\
\hline \multirow[t]{2}{*}{ Liver } & MK-4 & 0.026 & 0.823 & 0.566 & 0.026 & 0.260 \\
\hline & MK-7 & 0.050 & 0.914 & 0.592 & 0.056 & 0.195 \\
\hline \multirow[t]{2}{*}{ Kidney } & MK-4 & 0.006 & 0.597 & 0.851 & 0.002 & 0.228 \\
\hline & MK-7 & $-^{\mathrm{a}}$ & $-^{\mathrm{a}}$ & $-^{\mathrm{a}}$ & $-^{\mathrm{a}}$ & $-^{\mathrm{a}}$ \\
\hline \multirow[t]{2}{*}{ Skin } & MK-4 & 0.000 & 0.006 & 0.664 & 0.000 & 0.030 \\
\hline & MK-7 & 0.013 & 0.980 & 0.482 & 0.002 & $-^{\mathrm{a}}$ \\
\hline \multirow[t]{2}{*}{ Heart } & MK-4 & 0.000 & 0.069 & 0.885 & 0.002 & 0.016 \\
\hline & MK-7 & 0.801 & 0.995 & 0.506 & 0.558 & 0.687 \\
\hline \multirow[t]{2}{*}{ Brain } & MK-4 & 0.000 & 0.204 & 0.805 & 0.003 & 0.001 \\
\hline & MK-7 & $-^{\mathrm{a}}$ & $-^{\mathrm{a}}$ & $-^{\mathrm{a}}$ & $-^{\mathrm{a}}$ & $-^{\mathrm{a}}$ \\
\hline
\end{tabular}

compared. In addition, this technique measures the entire muzzle calcification and does not rely on sectioning and sampling as histological techniques do.

Our in vivo measurements clearly showed that a 100 -fold increased MK-7 concentration in the diet did not change the pace of calcification of whisker sinus capsules. To confirm and extend these findings, we measured ex vivo the calcification in arteries in the kidney cortex. This vascular calcification phenotype was not affected by MK-7 supplementation either.

It may be argued that we started the dietary intervention too late to obtain an effect of vitamin K. Supplementation of vitamin $\mathrm{K}$ may have effect only in initial stages and may not affect pathology once calcification has started. However, micro-CT scans taken before the start of the diet showed that not all whisker sinuses had begun to mineralize at that point. During our diet period, clearly both volume and number of calcified whiskers increased (Fig. 3). Additionally, in rats suffering from medial elastocalcinosis, 6 weeks of vitamin $\mathrm{K}$ treatment resulted in some $40 \%$ reduction of preformed calcifications [32]. Taken together, our conclusion of lack of an effect of vitamin $\mathrm{K}$ probably holds true for both ongoing mineralization and de novo mineralization of whiskers capsules in PXE.

In addition, the objection may be raised that the diet was not given long enough to take effect. We consider this to be unlikely. The diet clearly increased tissue levels of vitamin K, measured at the end of the diet. When we compare the progress in calcification in the three intervals between the micro-CT scans, we did not notice a slower pace of calcification in the $100 \times \mathrm{MK}-7$ diet group in the last interval (Fig. 4). In addition, in a previous animal study, it was shown that a 4-week period of high vitamin $\mathrm{K}_{2}$ intake was sufficient to inhibit medial calcifications induced by coumarins [30].

MK-7 supplementation increased MK-4 tissue levels, irrespective of Abcc6 genotype

In wt mice, the $100 \times \mathrm{MK}-7$ diet caused higher levels of MK-7 in liver and skin. In other tissues, no increased MK-7 levels were found. Interestingly, MK-7 supplementation also raised MK-4 levels in the liver and in all extra-hepatic tissues investigated (skin, kidney, heart and brain). These
Fig. 7 MK-4 levels ( \pm s.d.) in liver and extra-hepatic tissues as function of diet and genotype. The $100 \times$ MK-7 diet increased MK-4 tissue levels both in wt and $A b c c \sigma^{-1}$ mice (for statistics, see Table 1)

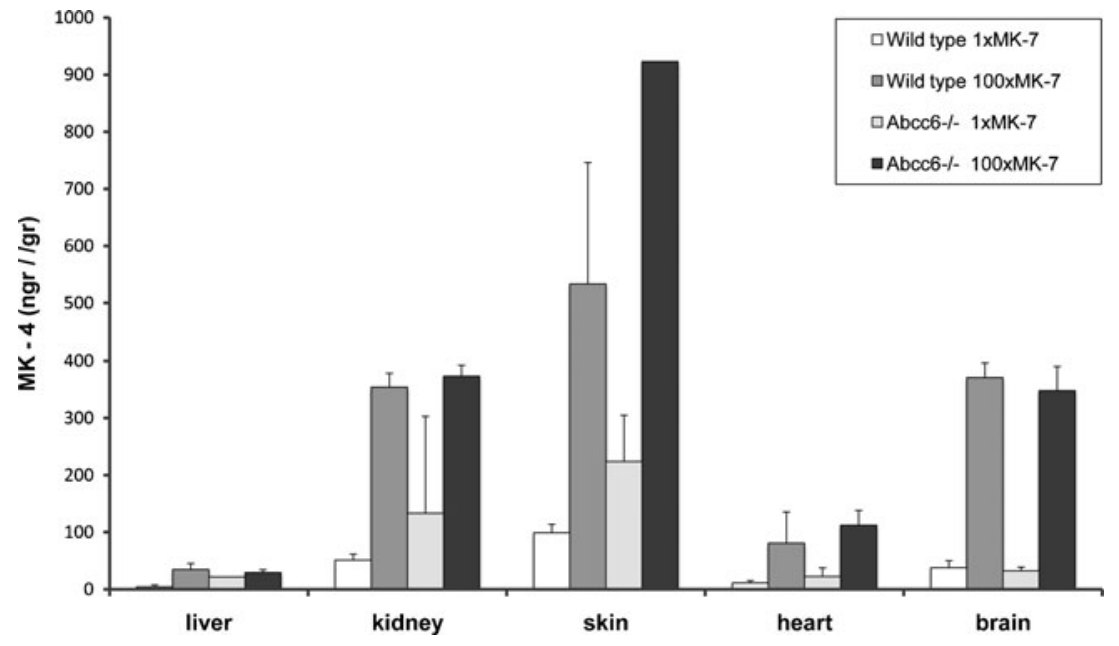


Fig. 8 MK-7 levels ( \pm s.d.) in liver and in extra-hepatic tissues as function of diet and genotype. MK-7 levels were highly variable. No differences were observed between the genotypes. A statistically significant effect of diet was found for skin and liver (for statistics, see Table 1)

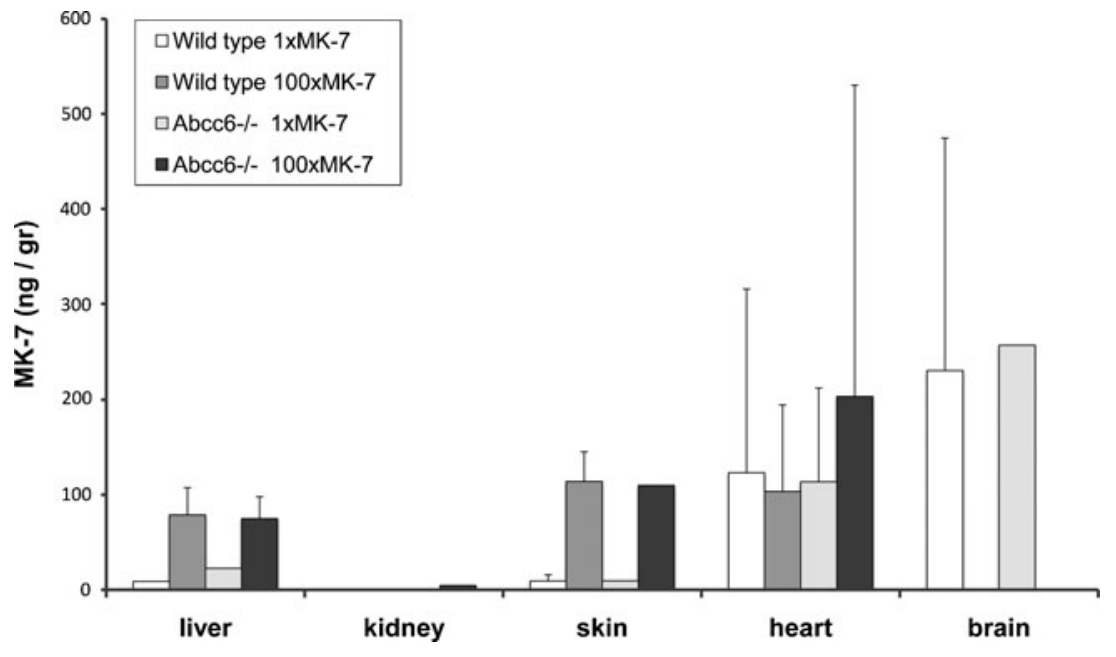

MK-4 measurements indicate that at least part of the supplied MK-7 is converted into MK-4. Thijssen et al. [33] previously demonstrated that all $\mathrm{K}$ vitamins can be converted into MK-4 via the intermediate product menadione $\left(\mathrm{K}_{3}\right)$. The side-chain removal most likely takes place in the enterocytes, after which the circulating $\mathrm{K}_{3}$ can be taken up and prenylated to MK-4 locally. In addition, our observation that the $100 \times \mathrm{MK}-7$ diet increased MK-7 (and not MK-6 or MK-5) in skin and liver suggests that MK-7 is also taken up without being converted.

According to the PXE-K hypothesis, Abcc6 transports vitamin $\mathrm{K}$ from the hepatocyte cytoplasm into the bloodstream. Since the liver efficiently clears vitamin $\mathrm{K}$ from the circulation, this transport is essential for the supply of extrahepatic tissues with vitamin $\mathrm{K}$. On the basis of the PXE-K hypothesis, we expected $A b c c \sigma^{--}$mice to have lower extrahepatic vitamin $\mathrm{K}$ levels than wt mice. However, we found that vitamin $\mathrm{K}$ levels were not reduced in $\mathrm{Abcc}^{-1}$ mouse tissues. In the $A b c c \sigma^{--}$skin, MK-4 level even appeared to be increased. Whether this particular finding occurred by chance or has biological significance is not known. In a pilot experiment preceding this study, we compared vitamin $\mathrm{K}$ levels between five wt and five $A b c c \sigma^{1-}$ male mice of 7 months old. No difference was found between the skin levels of $\mathrm{K}$ vitamins, including MK-4 (data not shown). Overall, the data suggest that Abcc6 genotype has no influence on MK-4 tissue levels. We also found that it had no influence on the increase in MK-4 levels that occurred by the dietary MK-7 supplementation. These findings suggest that, contrary to the PXE-K hypothesis, Abcc6 has no role in transport of vitamin $\mathrm{K}$ to extra-hepatic tissues.

Increased vitamin $\mathrm{K}$ tissue levels did not slow down mineralization

Vitamin $\mathrm{K}$ is needed as co-factor in the $\gamma$-glutamyl carboxylation-mediated activation of various proteins [34].
The calcification inhibitor MGP was found to be uncarboxylated and thus inactive in PXE patients [20]. Even though we failed to demonstrate a role of Abcc6 in transport of vitamin $\mathrm{K}$, it is still possible that vitamin $\mathrm{K}$ supplementation would increase MGP carboxylation and, in this way, alleviate PXE symptoms. Our dietary regime significantly (5-10-fold) increased MK-4 levels in extrahepatic tissue, both in wt and in $\mathrm{Abcc}^{/-}$mice. Yet, the increased MK-4 concentrations did not reduce ectopic calcification. This suggests that in our $A b c c \sigma^{-1}$ mice, local vitamin $\mathrm{K}$ concentration is not the limiting factor in preventing mineralization of connective tissue. This conclusion is supported by the fact that no correlation was found between MK-4 content and muzzle calcification in individual mice. In addition, the findings suggest that other forms of administration such as parental or intravenous administration may equally fail to halt this pathology.

In order to investigate directly whether vitamin $\mathrm{K}$ supplementation had changed the local status of MGP, we performed immunohistochemistry with conformationspecific antibodies for either ucMGP or cMGP on sections of aorta and muzzle. However, no clear immunostaining could be observed in wt or in $A b c c \sigma^{-1}$ tissue. Apparently, our material was not suited for this technique (e.g. caused by poor antigen preservation). The local carboxylation status of MGP during our dietary regime thus remained undetermined.

\section{Aetiology of PXE?}

Previous studies strongly suggested that PXE symptoms are caused by local tissue deficiency in vitamin $\mathrm{K}$ dependent protein carboxylation. These indications included (1) PXE-like features in patients with $G G C X$ mutations [18], (2) reduced $\gamma$-carboxylation of MGP in PXE patients [20] and (3) reduced serum levels of vitamin 
$\mathrm{K}$ in PXE patients [21]. The hypothesis that Abcc6 transports vitamin $\mathrm{K}$ and thereby distributes vitamin $\mathrm{K}$ to extra-hepatic tissues offers an elegant explanation for these data.

Yet, in the present study, we found no indications that Abcc6 plays a role in vitamin $\mathrm{K}$ transport and distribution. Certainly, our study has limitations. Some of these were already discussed above. We can add here that our study was done in the mouse model for PXE and that there may be (yet unknown) differences between mouse and man in vitamin $\mathrm{K}$ trafficking. Nonetheless, with the present knowledge, the $A b c c \sigma^{-}$ mouse appears to be a valid PXE model for our current studies: It resembles PXE in genotype and phenotype [7] including the undercarboxylation of MGP [22]. Moreover, as for vitamin $\mathrm{K}$ trafficking in mice, vitamin $\mathrm{K}$ tissue levels increased as a result of MK-7 supplementation, both in wt and in $A b c c \sigma^{-1}$ mice. Therefore, our conclusions obtained with the PXE mouse model likely have validity for the aetiology of PXE. They do not support the hypothesis of deficient vitamin $\mathrm{K}$ transport as a cause of PXE. Furthermore, while this study was under review, Li et al. [35] and Brampton et al. [36] reported that neither intravenous administration of a vitamin $\mathrm{K}$ conjugate (menadione gluthatione conjugate) nor dietary supplementation with MK-4 or $\mathrm{K}_{1}$ counteracted ectopic mineralization in the $\mathrm{Abcc \sigma}^{-1}$ mouse.

Other explanations must now be considered for the reduced vitamin $\mathrm{K}$-dependent protein carboxylation in PXE tissues. Instead of vitamin K, Abcc6 may transport another substance that directly or indirectly affects $\gamma$-carboxylation. For example, since it has been reported that increased oxidative stress occurs in PXE [37-40], it could be that Abcc6 transports a substance that affects oxidative stress levels. Increased numbers of free radicals will scavenge the reduced form of vitamin $\mathrm{K}$ and thereby prevent the $\gamma$-carboxylation. In this way, not amount but rather redox status of vitamin $\mathrm{K}$ determines PXE. Differential measurement of the redox forms of vitamin $\mathrm{K}$ in $A b c c \sigma^{-1-}$ mouse tissue may solve this issue.

\begin{abstract}
Acknowledgements and disclosure statement The authors thank Drs P. Borst, K. van de Wetering, S. Kaing and W. Verweij for discussion and comments. Financial support of the MD Fonds, Landelijke Stichting voor Blinden en Slechtzienden, Oogfonds Nederland, Stichting Blinden-Penning, Algemene Nederlandse Vereniging ter Voorkoming van Blindheid and Retina Nederland is gratefully acknowledged. The authors declare no conflict of interests related to this study.
\end{abstract}

Open Access This article is distributed under the terms of the Creative Commons Attribution Noncommercial License which permits any noncommercial use, distribution, and reproduction in any medium, provided the original author(s) and source are credited.

\section{References}

1. Goodman RM, Smith EW, Paton D, Bergman RA, Siegel CL, Ottesen OE, Shelley WM, Push AL, McKusick VA (1963) Pseudoxanthoma elasticum: a clinical and histopathological study. Medicine (Baltimore) 42:297-334

2. Hu X, Plomp AS, van Soest S, Wijnholds J, de Jong PT, Bergen AA (2003) Pseudoxanthoma elasticum: a clinical, histopathological, and molecular update. Surv Ophthalmol 48:424-438

3. Plomp AS, Hu X, de Jong PT, Bergen AA (2004) Does autosomal dominant pseudoxanthoma elasticum exist? Am J Med Genet A 126A:403-412. doi:10.1002/ajmg.a.20632

4. Finger RP, Charbel IP, Ladewig MS, Gotting C, Szliska C, Scholl HP, Holz FG (2009) Pseudoxanthoma elasticum: genetics, clinical manifestations and therapeutic approaches. Surv Ophthalmol 54:272-285. doi:10.1016/j.survophthal.2008.12.006

5. Bergen AA, Plomp AS, Schuurman EJ, Terry S, Breuning M, Dauwerse H, Swart J, Kool M, van Soest S, Baas F, ten Brink JB, de Jong PT (2000) Mutations in ABCC6 cause pseudoxanthoma elasticum. Nat Genet 25:228-231

6. Le Saux O, Urban Z, Tschuch C, Csiszar K, Bacchelli B, Quaglino D, Pasquali-Ronchetti I, Pope FM, Richards A, Terry S, Bercovitch L, De Paepe A, Boyd CD (2000) Mutations in a gene encoding an $\mathrm{ABC}$ transporter cause pseudoxanthoma elasticum. Nat Genet 25:223-227

7. Gorgels TG, Hu X, Scheffer GL, van der Wal AC, Toonstra J, de Jong PT, van Kuppevelt TH, Levelt CN, de Wolf A, Loves WJ, Scheper RJ, Peek R, Bergen AA (2005) Disruption of Abcc6 in the mouse: novel insight in the pathogenesis of pseudoxanthoma elasticum. Hum Mol Genet 14:1763-1773

8. Klement JF, Matsuzaki Y, Jiang QJ, Terlizzi J, Choi HY, Fujimoto N, Li K, Pulkkinen L, Birk DE, Sundberg JP, Uitto J (2005) Targeted ablation of the abcc6 gene results in ectopic mineralization of connective tissues. Mol Cell Biol 25:82998310

9. Borst P, Elferink RO (2002) Mammalian ABC transporters in health and disease. Annu Rev Biochem 71:537-592

10. Bergen AA, Plomp AS, Hu X, de Jong PT, Gorgels TG (2007) ABCC6 and pseudoxanthoma elasticum. Pflugers Arch 453:685691. doi:10.1007/s00424-005-0039-0

11. Hu X, Peek R, Plomp A, ten Brink J, Scheffer G, van Soest S, Leys A, de Jong PT, Bergen AA (2003) Analysis of the frequent R1141X mutation in the ABCC6 gene in pseudoxanthoma elasticum. Invest Ophthalmol Vis Sci 44:1824-1829

12. Hendig D, Langmann T, Kocken S, Zarbock R, Szliska C, Schmitz G, Kleesiek K, Gotting C (2008) Gene expression profiling of $\mathrm{ABC}$ transporters in dermal fibroblasts of pseudoxanthoma elasticum patients identifies new candidates involved in PXE pathogenesis. Lab Invest 88:1303-1315. doi:10.1038/labinvest.2008.96

13. Scheffer GL, Hu X, Pijnenborg AC, Wijnholds J, Bergen AA, Scheper RJ (2002) MRP6 (ABCC6) detection in normal human tissues and tumors. Lab Invest 82:515-518

14. Ilias A, Urban Z, Seidl TL, Le Saux O, Sinko E, Boyd CD, Sarkadi B, Varadi A (2002) Loss of ATP-dependent transport activity in pseudoxanthoma elasticum-associated mutants of human ABCC6 (MRP6). J Biol Chem 277:16860-16867

15. Uitto J, Pulkkinen L, Ringpfeil F (2001) Molecular genetics of pseudoxanthoma elasticum: a metabolic disorder at the environment-genome interface? Trends Mol Med 7:13-17

16. Le Saux O, Bunda S, VanWart CM, Douet V, Got L, Martin L, Hinek A (2006) Serum factors from pseudoxanthoma elasticum patients alter elastic fiber formation in vitro. J Invest Dermatol 126:1497-1505. doi:10.1038/sj.jid.5700201 
17. Jiang Q, Endo M, Dibra F, Wang K, Uitto J (2009) Pseudoxanthoma elasticum is a metabolic disease. J Invest Dermatol 129:348-354. doi:10.1038/jid.2008.212

18. Vanakker OM, Martin L, Gheduzzi D, Leroy BP, Loeys BL, Guerci VI, Matthys D, Terry SF, Coucke PJ, Pasquali-Ronchetti I, De PA (2007) Pseudoxanthoma elasticum-like phenotype with cutis laxa and multiple coagulation factor deficiency represents a separate genetic entity. J Invest Dermatol 127:581-587. doi:10.1038/sj.jid.5700610

19. Luo G, Ducy P, McKee MD, Pinero GJ, Loyer E, Behringer RR, Karsenty G (1997) Spontaneous calcification of arteries and cartilage in mice lacking matrix GLA protein. Nature 386:7881. doi: $10.1038 / 386078 \mathrm{a} 0$

20. Gheduzzi D, Boraldi F, Annovi G, DeVincenzi CP, Schurgers LJ, Vermeer C, Quaglino D, Ronchetti IP (2007) Matrix Gla protein is involved in elastic fiber calcification in the dermis of pseudoxanthoma elasticum patients. Lab Invest 87:998-1008. doi:10.1038/labinvest.3700667

21. Vanakker OM, Martin L, Schurgers LJ, Quaglino D, Costrop L, Vermeer C, Pasquali-Ronchetti I, Coucke PJ, De PA (2010) Low serum vitamin $\mathrm{K}$ in PXE results in defective carboxylation of mineralization inhibitors similar to the GGCX mutations in the PXE-like syndrome. Lab Invest. doi:10.1038/labinvest.2010.68

22. Li Q, Jiang Q, Schurgers LJ, Uitto J (2007) Pseudoxanthoma elasticum: reduced gamma-glutamyl carboxylation of matrix gla protein in a mouse model $\left(\mathrm{Abcc}^{-1-}\right)$. Biochem Biophys Res Commun 364:208-213. doi:10.1016/j.bbrc.2007.09.122

23. Borst P, van de Wetering K, Schlingemann R (2008) Does the absence of ABCC6 (multidrug resistance protein 6) in patients with Pseudoxanthoma elasticum prevent the liver from providing sufficient vitamin $\mathrm{K}$ to the periphery? Cell Cycle 7:1575-1579

24. Shearer MJ, Newman P (2008) Metabolism and cell biology of vitamin K. Thromb Haemost 100:530-547

25. Schurgers LJ, Teunissen KJ, Hamulyak K, Knapen MH, Vik H, Vermeer C (2007) Vitamin K-containing dietary supplements: comparison of synthetic vitamin $\mathrm{K} 1$ and natto-derived menaquinone7. Blood 109:3279-3283. doi:10.1182/blood-2006-08-040709

26. Schurgers LJ, Vermeer C (2000) Determination of phylloquinone and menaquinones in food. Effect of food matrix on circulating vitamin K concentrations. Haemostasis 30:298-307

27. Jiang Q, Li Q, Uitto J (2007) Aberrant mineralization of connective tissues in a mouse model of pseudoxanthoma elasticum: systemic and local regulatory factors. J Invest Dermatol 127:1392-1402. doi:10.1038/sj.jid.5700729

28. Ronden JE, Thijssen HH, Vermeer C (1998) Tissue distribution of $\mathrm{K}$-vitamers under different nutritional regimens in the rat. Biochim Biophys Acta 1379:16-22

29. Gorgels TG, Waarsing JH, De WA, ten Brink JB, Loves WJ, Bergen AA (2010) Dietary magnesium, not calcium, prevents vascular calcification in a mouse model for pseudoxanthoma elasticum. J Mol Med. doi:10.1007/s00109-010-0596-3

30. Spronk HM, Soute BA, Schurgers LJ, Thijssen HH, De Mey JG, Vermeer C (2003) Tissue-specific utilization of menaquinone-4 results in the prevention of arterial calcification in warfarin-treated rats. J Vasc Res 40:531-537. doi:10.1159/ 000075344

31. Rice FL, Mance A, Munger BL (1986) A comparative light microscopic analysis of the sensory innervation of the mystacial pad. I. Innervation of vibrissal follicle-sinus complexes. J Comp Neurol 252:154-174. doi:10.1002/cne.902520203

32. Schurgers LJ, Spronk HM, Soute BA, Schiffers PM, DeMey JG, Vermeer C (2007) Regression of warfarin-induced medial elastocalcinosis by high intake of vitamin $\mathrm{K}$ in rats. Blood 109:28232831. doi:10.1182/blood-2006-07-035345

33. Thijssen HH, Vervoort LM, Schurgers LJ, Shearer MJ (2006) Menadione is a metabolite of oral vitamin K. Br J Nutr 95:260 266

34. Vermeer C (1990) Gamma-carboxyglutamate-containing proteins and the vitamin K-dependent carboxylase. Biochem J 266:625636

35. Jiang Q, Li Q, Grand-Pierre AE, Schurgers LJ, Uitto J (2011) Administration of vitamin $\mathrm{K}$ does not counteract the ectopic mineralization of connective tissues in Abcc $6\left(^{-/}\right)$mice, a model for pseudoxanthoma elasticum. Cell Cycle 10:701-707

36. Brampton C, Yamaguchi Y, Vanakker O, Van LL, Chen LH, Thakore M, De PA, Pomozi V, Szabo PT, Martin L, Varadi A, Le Saux O (2011) Vitamin K does not prevent soft tissue mineralization in a mouse model of pseudoxanthoma elasticum. Cell Cycle 10:1810-1820

37. Pasquali-Ronchetti I, Garcia-Fernandez MI, Boraldi F, Quaglino D, Gheduzzi D, De Vincenzi PC, Tiozzo R, Bergamini S, Ceccarelli D, Muscatello U (2006) Oxidative stress in fibroblasts from patients with pseudoxanthoma elasticum: possible role in the pathogenesis of clinical manifestations. J Pathol 208:54-61. doi:10.1002/path. 1867

38. Garcia-Fernandez MI, Gheduzzi D, Boraldi F, Paolinelli CD, Sanchez P, Valdivielso P, Morilla MJ, Quaglino D, Guerra D, Casolari S, Bercovitch L, Pasquali-Ronchetti I (2008) Parameters of oxidative stress are present in the circulation of PXE patients. Biochim Biophys Acta 1782:474-481. doi:10.1016/j. bbadis.2008.05.001

39. Li Q, Jiang Q, Uitto J (2008) Pseudoxanthoma elasticum: oxidative stress and antioxidant diet in a mouse model $\left(\right.$ Abcc $\left.^{-1}\right)$. J Invest Dermatol 128:1160-1164. doi:10.1038/sj.jid.5701145

40. Zarbock R, Hendig D, Szliska C, Kleesiek K, Gotting C (2007) Pseudoxanthoma elasticum: genetic variations in antioxidant genes are risk factors for early disease onset. Clin Chem 53:1734-1740. doi:10.1373/clinchem.2007.088211 